\title{
Comparison of Real Cost Versus the Indonesian Case Base Groups (INA-CBGs) Tariff Rates Among Patients of High- Incidence Cancers Under the National Health Insurance Scheme
}

\author{
Satibi Satibi ${ }^{1 *}$, Tri Murti Andayani ${ }^{1}$, Dwi Endarti ${ }^{1}$, I Putu Tangkas Suwantara ${ }^{2}$, \\ Ni Putu Wintariani², Ni Putu Dewi Agustini²
}

\begin{abstract}
Background: The national health insurance of Indonesia has implemented the Indonesian Case Base Groups (INA-CBGs) tariff rates for healthcare payment. However, there is still problem of difference between the real cost of healthcare and the INA-CBGs tariff rates. This study aimed to evaluate the real cost of healthcare in comparison with the INA-CBG's tariff rates and to analyze factors associating with the real cost. The study focus on healthcare cost of non-chemotherapy expenditure among patients of high-incidence cancers having chemotherapy covered by the national health insurance. Methods: The study was conducted from the perspective of healthcare provider. Costs data was obtained from hospital billing of Sanglah hospital, a referral hospital in Bali Provincein the period of January - July 2014. The data involved 383, 161, and 152 of in-patient breast cancer cases, cervical cancer cases, and nasopharyngeal cancer cases, respectively. Descriptive statistic was used to analyze patients characteristics, one sample t-test was used to analyze the mean difference of healthcare cost based on real cost and INA-CBG's tariff rates, and finally, bivariate analysis was used to examine relationship between patients' characteristics and the real cost. Results: The study shows there were significant differences of non-chemotherapy expenditures based on the real cost and INA-CBG's tariff rates, in which the costs were lower for the real cost. Factors which significantly associated with the real cost were number of procedure, type of hospitalized room, and length of stay. Conclusions: The study supports the necessary of evaluation of the INA-CBG's tariff rates to adjust to the real healthcare expenditure. On the other hand, the hospital needs to evaluate the service quality of patient treatment by optimizing budget allocated by the health insurance.
\end{abstract}

Keywords: Real cost- INA-CBG's- chemotherapy- breast cancer- cervical cancer- nasopharyngeal cancer- Indonesia

Asian Pac J Cancer Prev, 20 (1), 117-122

\section{Introduction}

Cancer diseases are the major cause of health problems, including the burden of morbidity, mortality, and high cost of treatment. Breast cancer and cervical cancer are the most highly incidence of cancer among female in Southeast Asia, including Indonesia (Moore et al., 2010). In Indonesia, the incidence and mortality rate of breast cancer are 39.9 per 100,000 populations and 16.1 per 100,000 populations, respectively the incidence and mortality rate of cervical cancer are 17 per 100,000 populations and 7.7 per 100,000 populations, respectively; the incidence and mortality rate of nasopharyngeal cancer are 5.3 per 100,000 populations and 3.0 per 100,000 populations, respectively (Ferlay et al., 2012). Based on Indonesian Cancer Registry System, which first started by hospital based, then expanded to be population-based, breast cancer, cervical cancer, and pharyngeal cancer were among the leading cancers due to the incidences (Wahidin et al., 2012). There are three main strategies for cancer therapy, including surgery, radiotherapy, and chemotherapy (Baba et al., 2007). The costs for cancer treatment is indeed high. WHO estimated the total annual economic cost of cancer in 2010 was approximately US\$ 1.16 trillion (WHO, 2018). In addition, the total economic impact of premature death and disability from cancer worldwide was $\$ 895$ billion in 2008 (ACS, 2010).

Following the Indonesian Law No. 40/2004 about national social security system, in which the country was going to move towards Universal Health Coverage (UHC), the government employed the Social Security Administrative Body (hereafter referred to as BPJS) to manage Indonesian national health insurance programme. The National Health Insurance Scheme (JKN) was 
launched on 1 January 2014 and targeted to the achievement of UHC by 2019 (National Team for The Acceleration of Poverty Reduction, 2015). At the hospital level, JKN team has developed the INA-CBGs (Indonesian - Case Base Groups) tariff rates for healthcare payment system, which is a prospective payment method. The INA-CBGs were developed with the participation of organizations of health professionals and the Association of Hospitals, as well as extensive review of treatment standards and payments in diverse situations (Mboi, 2015). The Ina-CBGs tariff rates are based on tariff of diagnosis grouping using clinical and homogeneity of resource utilization approaches. The healthcare payment follows the CBGs code based on patient's disease diagnose and does not consider the costs based on health services received by each patient (Ministry of Health of Republic of Indonesia, 2014). There are two hospital payment methods, namely the retrospective payment method and prospective payment methods. Retrospective payment method is a method of payment made for health services provided to patients based on each service activity provided, the more health services provided the greater the costs to be paid. An example of a retrospective payment pattern is Fee For Services (FFS). Prospective payment method is a method of payment made for health services whose amount is known before health services are provided. Examples of prospective payments are the global budget, Per diem, Capitation and case based payment. There is no perfect financing system, each financing system has advantages and disadvantages. Example of countries employs capitation are Denmark, the UK, and Thailand; countried employs case-based payment are Australia, Hungary, and the United States; and countries employes fee-for-service payment mechanisms are Germany, Korea, and Taiwan (Waters et al., 2004).

It is recognized that there are obstacles of the INACBGs implementation. One of the problems is regarding the tariff, in which there are often differences of healthcare expenditures based on the real costs and the INA-CBG's tariff rates (Ambarriani, 2014). This study aimed to evaluate the real cost of healthcare in comparison with the INA-CBG's tariff rates and to analyze factors affecting the real cost. The study focus on healthcare cost of non-chemotherapy expenditure among patients of highincidence cancers having chemotherapy covered by the national health insurance.

\section{Materials and Methods}

\section{Methods}

The study gained ethical clearance approval from the Ethics Team of the Faculty of Medicine, Udayana University with approval number: 899/UN.14.2/ Litbang/ 2014. The study was conducted from the perspective of healthcare provider. We measured the cost of nonchemotherapy components among the cancer patient undergoing chemotherapy. We then also revealed the same cost basen on INA-CBGs tariff rates. Cost data for calculation of real health expenditures was obtained from hospital billing of Sanglah hospital, a referral hospital in Bali province-Indonesia in the period of January - July 2014. The data involved 383, 161, and
152 in-patient breast cancer cases, cervical cancer cases, and nasopharyngeal cancer cases, respectively. The data included direct medical costs required by hospital to treat each patient as recorded in the hospital billing archives, including costs of drugs and medical devices, hospitalization, laboratory, and administration. Meanwhile, healthcare expenditure estimation was based on the INA-CBG's tariff rates following the code obtained from disease diagnose written in the medical record, in which the rates has been set in the Republic of Indonesia's health minister's regulation number 69 of 2013 (MoH of Republic of Indonesia, 2013). The rates were determined by an INA-CBGs code consisting of four digits financing components written in alphanumeric code. Each digit explain case-mix main group (CMG), case-type group, case-based group (CBG), and severity level. CMG related with organ system that classified into 31 groups, case-type group indicates 9 types of treatment and procedure, CBG refer to specific case-based group denoted with numeric from 01 to 99 , and lastly severity level (SL) indicates disease cases severity associated with a secondary diagnosis that can prolong hospitalized patient's length of stay (LOS) and caused rates varies on each case-mix main group (CMG). The level of severity affect by complications and co-morbidity. Hospitalize patient grouped into 3 categories level of severity, namely level I (mild) which is diagnosis without complications and co-morbidity, level II (medium) which is diagnosis with mild complications and co-morbidity, and level III (severe) which is diagnosis with major complications and co-morbidity (Puspitorini et al., 2017). For in-patient cancer treatment, the INA-CBGs consists of three groups, namely C-4-13-I (severity level I), C-4-13-II (severity level II), and C-4-13-III (severity level III). The cost of chemotherapy is excluded in those tariffs and reimbursed separately (MoH of Republic of Indonesia, 2014). In addition, the patient's characteristics data including type of hospitalized room, disease severity level, number of secondary diagnoses, and number of treatment procedures were also recorded from the medical record.

Descriptive statistic was used to analyse patients' characteristics and furthermore presented in terms of percentage of each category of all characteristics Total treatment cost of all patients in each type of cancer and level of severity measured from real costs were presented and compared with those measured from INA-CBGs tariffs to examine the defict or surplus budget from the perspective of the hospital. Furthermore, the mean treatment costs per episode in each type of cancer and level of severity measured from real costs were presented and compared with those measured from INA-CBGs tariffs to examine the difference between real cost and INA-CBGs tariff rates. In addition, inferential statistics using one sample t-test was used to analyse the mean difference of healthcare cost based on real cost and INA-CBG's tariff rates; while bivariate analysis was used to examine the relationship between patient's characteristics and the real cost in each group based on the severity level. The relationships were examined using bivariate analysis employing Pearson correlation. 


\section{Results}

The patients' characteristics are presented in Table 1. We did not conduct statistical analysis to assign the different of patients' characteristics among categories and type of cancers, however it seemed that in general for the three type of cancers, most of patients were admitted in 3rd type of hospitalized room, had 1st severity level, did not have secondary diagnose, and received only 1 type of procedure of treatment.
Table 2 shows the different amount of total non-chemotherapy expenditure in cancer patients receiving chemotherapy based on the real cost calculation and the INA-CBG's tariff estimation. The amounts were all positive indicating that the real costs were lower compared to the INA-CBG's tariff rates or there was a surplus budget from the perspective of the hospital. For the period of 6 months (January - July 2014), there were total surplus of IDR 1,900,593,679, IDR 738,043,940, and IDR 539,819,406 for for treatment of breast cancer,

Table 1. Patients' Characteristics

\begin{tabular}{|c|c|c|c|c|}
\hline \multirow[t]{3}{*}{ Characteristic } & \multirow[t]{3}{*}{ Categorization } & \multicolumn{3}{|c|}{ Percentage of cases based on cancer type (\%) } \\
\hline & & Breast cancer & $\begin{array}{l}\text { Cervical } \\
\text { cancer }\end{array}$ & $\begin{array}{l}\text { Nasopharyngeal } \\
\text { cancer }\end{array}$ \\
\hline & & $(\mathrm{n}=383)$ & $(n=161)$ & $(\mathrm{n}=152)$ \\
\hline \multirow[t]{3}{*}{ Disease severity level based on INA-CBG category } & C-4-13-I & 63 & 81 & 72 \\
\hline & C-4-13-II & 28 & 4 & 26 \\
\hline & C-4-13-III & 9 & 1 & 8 \\
\hline \multirow[t]{3}{*}{ Type of hospitalized room } & 1st Class & 29 & 24 & 18 \\
\hline & 2nd class & 7 & 3 & 14 \\
\hline & 3rd class & 64 & 68 & 74 \\
\hline \multirow[t]{5}{*}{ Number of secondary diagnoses } & No secondary diagnose & 54 & 55 & 82 \\
\hline & 1 secondary diagnose & 32 & 2 & 14 \\
\hline & 2 secondary diagnose & 11 & 24 & 2 \\
\hline & 3 secondary diagnose & 2 & 0 & 2 \\
\hline & $>3$ secondary diagnose & 1 & 0 & 0 \\
\hline \multirow[t]{4}{*}{ Number of procedure } & 1 procedure & 71 & 57 & 64 \\
\hline & 2 procedure & 22 & 15 & 32 \\
\hline & 3 procedure & 5 & 15 & 11 \\
\hline & $>3$ procedure & 1 & 7 & 64 \\
\hline
\end{tabular}

Table 2. Different of Total Cost for All Patients between the Real Cost Calculation and the INA-CBGs Tariff Estimation

\begin{tabular}{|c|c|c|c|c|c|c|}
\hline \multirow{2}{*}{$\begin{array}{l}\text { Severity level and type } \\
\text { of hospitalized room }\end{array}$} & \multicolumn{2}{|c|}{ Breast cancer } & \multicolumn{2}{|c|}{ Cervical cancer } & \multicolumn{2}{|c|}{ Nasopharyngeal cancer } \\
\hline & $\begin{array}{c}\text { Number of } \\
\text { cases }(n=383)\end{array}$ & $\begin{array}{l}\text { Difference of } \\
\text { costs (IDR)* }\end{array}$ & $\begin{array}{c}\text { Number of } \\
\text { cases }(n=161)\end{array}$ & $\begin{array}{l}\text { Difference of } \\
\text { costs (IDR)* }\end{array}$ & $\begin{array}{c}\text { Number of } \\
\text { cases }(n=152)\end{array}$ & $\begin{array}{l}\text { Difference of } \\
\text { costs (IDR)* }\end{array}$ \\
\hline \multicolumn{7}{|l|}{ Severity level I (C-4-13-I) } \\
\hline 1st class & 58 & $237,786,368$ & 21 & $77,021,099$ & 34 & $63,378,719$ \\
\hline 2nd class & 11 & $40,888,130$ & 11 & $40,924,685$ & 3 & $11,164,041$ \\
\hline 3rd class & 173 & $552,010,986$ & 77 & $248,472,471$ & 94 & $265,353,088$ \\
\hline Total of severity level I & 242 & $830,685,484$ & 109 & $366,418,255$ & 131 & $337,895,848$ \\
\hline \multicolumn{7}{|l|}{ Severity level II (C-4-13-II) } \\
\hline 1 st class & 47 & $388,705,874$ & 4 & $29,467,328$ & 6 & $36,291,628$ \\
\hline 2nd class & 13 & $97,195,907$ & 8 & $58,917,239$ & 0 & n.a \\
\hline 3rd class & 47 & $301,217,583$ & 27 & $170,277,952$ & 0 & n.a \\
\hline Total of severity level II & 107 & $787,119,364$ & 39 & $258,662,519$ & 6 & $36,291,628$ \\
\hline \multicolumn{7}{|l|}{ Severity level III(C-4-13-III) } \\
\hline 1 st class & 7 & $74,148,926$ & 2 & $20,903,495$ & 3 & $34,434,030$ \\
\hline 2nd class & 1 & $9,127,349$ & 2 & $19,591,972$ & 2 & $13,562,874$ \\
\hline 3rd class & 26 & $199,512,556$ & 8 & $72,467,699$ & 13 & $84,122,496$ \\
\hline Total of severity level III & 34 & $282,788,831$ & 12 & $112,963,166$ & 18 & $165,631,930$ \\
\hline Total of all severities & 383 & $1,900,593,679$ & 160 & $738,043,940$ & 155 & $539,819,406$ \\
\hline
\end{tabular}

*Difference of cost, real cost calculation; INA-CBGs tariff rate. n.a, not applicable 
Table 3. Comparison of Real Cost Versus INA-CB's Tariff Rates per Episode of Treatment

\begin{tabular}{|c|c|c|c|c|c|c|c|}
\hline \multirow{2}{*}{$\begin{array}{l}\text { Severity level and type } \\
\text { of hospitalized room }\end{array}$} & \multirow{2}{*}{$\begin{array}{l}\text { Method of cost } \\
\text { measurement }\end{array}$} & \multicolumn{2}{|c|}{ Breast cancer } & \multicolumn{2}{|c|}{ Cervical cancer } & \multicolumn{2}{|c|}{ Nasopharyngeal cancer } \\
\hline & & $\begin{array}{l}\text { Mean cost } \\
\text { (IDR) }\end{array}$ & $\mathrm{P}^{*}$ & $\begin{array}{l}\text { Mean cost } \\
\text { (IDR) }\end{array}$ & $\mathrm{P}^{*}$ & $\begin{array}{l}\text { Mean cost } \\
\text { (IDR) }\end{array}$ & $\mathrm{P}^{*}$ \\
\hline \multicolumn{8}{|c|}{ Severity level I (C-4-13-I) } \\
\hline \multirow[t]{2}{*}{ 1st class } & Real cost & $1,109,456$ & 0.00 & $1,506,112$ & 0.00 & $1,580,435$ & 0.00 \\
\hline & INA-CBG's tariff & $5,209,221$ & & $5,173,784$ & & $5,209,221$ & \\
\hline \multirow[t]{2}{*}{ 2nd class } & Real cost & 753,489 & 0.00 & 676,967 & 0.00 & 743,699 & 0.00 \\
\hline & INA-CBG's tariff & $4,465,046$ & & $4,397,394$ & & $4,465,046$ & \\
\hline \multirow[t]{2}{*}{ 3rd class } & Real cost & 530,056 & 0.00 & 573,489 & 0.00 & 897,966 & 0.00 \\
\hline & INA-CBG's tariff & $3,720,871$ & & $3,759,034$ & & $3,720,871$ & \\
\hline \multicolumn{8}{|c|}{ Severity level II (C-4-13-II) } \\
\hline \multirow[t]{2}{*}{ 1st class } & Real cost & $1,533,496$ & 0.00 & $1,736,727$ & 0.00 & & \\
\hline & INA-CBG's tariff & $9,803,834$ & & $9,103,560$ & & & \\
\hline \multirow[t]{2}{*}{ 2nd class } & Real cost & 926,679 & 0.00 & 863,563 & 0.00 & & \\
\hline & INA-CBG's tariff & $8,403,287$ & & $8,228,218$ & & & \\
\hline \multirow[t]{2}{*}{ 3rd class } & Real cost & 593,853 & 0.00 & 696,147 & 0.00 & 954,133 & 0.00 \\
\hline & INA-CBG's tariff & $7,002,738$ & & $7,002,738$ & & $7,002,738$ & \\
\hline \multicolumn{8}{|c|}{ Severity level III(C-4-13-III) } \\
\hline \multirow[t]{2}{*}{ 1st class } & Real cost & $2,943,706$ & 0.00 & $1,150,889$ & 0.04 & $2,058,400$ & 0.00 \\
\hline & INA-CBG's tariff & $13,536,410$ & & $11,602,638$ & & $13,536,410$ & \\
\hline \multirow[t]{2}{*}{ 2nd class } & Real cost & 564,528 & & 839,765 & 0.02 & $4,821,200$ & 0.16 \\
\hline & INA-CBG's tariff & $11,602,637$ & & $10,635,751$ & & $11,602,637$ & \\
\hline \multirow[t]{2}{*}{ 3rd class } & Real cost & $1,995,305$ & 0.00 & 610,402 & 0.00 & $3,197,904$ & 0.00 \\
\hline & INA-CBG's tariff & $9,668,865$ & & $9,668,865$ & & $9,668,865$ & \\
\hline
\end{tabular}

cervical cancer, and nasopharyngeal cancer, respectively.

Table 3 describes the comparison of mean cost of non-chemotherapy expenditure in cancer patients receiving chemotherapy based on the real cost calculation and the INA-CBG's tariff estimation. There were significantly differences of the mean cost of non-chemotherapy expenditure between the real cost calculation and the INA-CBG's tariff rates in almost all group of severities and hospitalized classes of the three type of cancers $(p<0.05)$, except in the 2nd class and severity level III of nasopharyngeal cancer $(\mathrm{p}>0.05)$. The real costs were considerably lower than the INA-CBG's tariff rates.

Table 4. Correlation between the Patient's Characteristic and the Real Cost of Non-Chemotherapy Expenditure in Cancer Patients Receiving Chemotherapy

\begin{tabular}{|c|c|c|c|c|c|c|c|c|c|}
\hline \multirow[t]{2}{*}{ Patient characteristic } & \multicolumn{3}{|c|}{ Breast cancer } & \multicolumn{3}{|c|}{ Cervical cancer } & \multicolumn{3}{|c|}{ Nasopharyngeal cancer } \\
\hline & $\mathrm{n}$ & $\mathrm{r}$ & $\mathrm{p}$ & $\mathrm{n}$ & $\mathrm{r}$ & $\mathrm{p}$ & $\mathrm{n}$ & $\mathrm{r}$ & $\mathrm{p}$ \\
\hline Severity level I & 242 & & & 110 & & & 130 & & \\
\hline LOS & & 0.16 & 0.02 & & 0.07 & 0.47 & & 0.519 & 0.03 \\
\hline Number of secondary diagnoseł & & -0.05 & 0.48 & & 0.05 & 0.62 & & 0.362 & 0.20 \\
\hline Number of procedureł & & 0.29 & 0.00 & & 0.24 & 0.01 & & 0.557 & 0.00 \\
\hline Type of hospitalized room\# & & 0.38 & 0.00 & & 0.60 & 0.00 & & 0.568 & 0.00 \\
\hline Severity level II & 107 & & & 39 & & & 6 & & \\
\hline LOSł & & 0.41 & 0.00 & & 0.65 & 0.00 & & 0.846 & 0.00 \\
\hline Number of secondary diagnoseł & & 0.29 & 0.00 & & -0.11 & 0.49 & & 0.327 & 0.47 \\
\hline Number of proceduret & & 0.39 & 0.00 & & 0.60 & 0.00 & & 0.321 & 0.48 \\
\hline Type of hospitalized room\# & & 0.42 & 0.00 & & 0.50 & 0.00 & & n.a & n.a \\
\hline Severity level III & 34 & & & 12 & & & 16 & & \\
\hline LOS & & 0.53 & 0.00 & & 0.39 & 0.21 & & 0.587 & 0.04 \\
\hline Number of secondary diagnoseł & & 0.21 & 0.24 & & 0.23 & 0.46 & & 0.401 & 0.12 \\
\hline Number of proceduret & & 0.38 & 0.03 & & 0.60 & 0.04 & & 0.147 & 0.71 \\
\hline Type of hospitalized room\# & & 0.34 & 0.05 & & 0.80 & 0.00 & & 0.134 & 0.73 \\
\hline
\end{tabular}

1, Numerical data: the higher number indicates worse status; \#, Categorical data: the higher level indicates worse status. 
Table 4 presents the relationship between patients' characteristics and the real costs of non-chemotherapy expenditure in cancer patients receiving chemotherapy. In breast cancer cases, patients' characteristics which had significant relationship with the real costs were length of stay, number of procedure, and type of hospitalized room for cases with severity level I; length of stay, number of secondary diagnose, number of procedure, and type of hospitalized room for cases with severity level II; length of stay, number of procedure, and type of hospitalized room for cases with severity level III. Meanwhile, in cervical cancer cases, patients' characteristics which had significant relationship with the real costs were number of procedure, and type of hospitalized room for cases with severity level I; length of stay, number of procedure, and type of hospitalized room for cases with severity level II; number of procedure, and type of hospitalized room for cases with severity level III. Finally, in nasopharyngeal cancer cases, patients' characteristics which had significant relationship with the real costs were length of stay, number of procedure, and type of hospitalized room for cases with severity level I; and length of stay for cases with severity level II and III. In general, it can be said the patients' characteristics which mostly affect the real cost of non-chemotherapy expenditure in cancer patients receiving chemotherapy were length of stay, number of procedure, and type of hospitalized room.

\section{Discussion}

Most of patients were in the 3rd class of hospitalized room type since the proportion of patients covered by BPJS in the 3rd class was the highest. Sanglah hospital in Bali province, Indonesia is one of regional referral hospital for patients using BPJS health insurance scheme. Most of breast cancer cases were in the severity level I (C-4-13-I). This can indicate the successful of breast cancer screening program that the women can detect the disease earlier. Treatment by health provider (hospital) also contribute to the lower number of cancer cases in severity level II and III because the success of treatment for cancer cases in mild severity level will prevent the disease progression to the severity level of moderate and severe. The JKN supports cancer patients to seek treatment since they do not worry about the cost of treatment because the BPJS will cover their treatment costs.

In all groups of severity level and hospitalized room class of the three cancer cases in the study, the different amounts of the real costs of non-chemotherapy expenditure and the INA-CBG's tariff rates were positive or in other words, the real costs were lower as compared to the INA-CBG's tariff rates. For the period of 6 months, the hospital surplus due to difference costs between real costs and the INA-CBGs tariff rates were quite big especially for breast cancer cases due to the highest cases as compared to cervical cancer and nasopharyngeal cancer. The mean costs of non-chemotherapy expenditures based on the real cost calculation and the INA-CBG's tariff rates were significantly different in which the real costs were lower as compared to the INA-CBG's tariff rates in the three type of cancer cases. With regard to the type of hospitalized room class, both the real costs and the INA-CBG's tariff rates were higher in class I, and decreasing in class II and III. Furthermore, the costs in severity level I were the lowest and increasing for the severity level II and III due to the co-morbidity and complication of the diseases which need more procedures/services of treatment and longer of the length of stay in hospital. Findings of this study were inline with the previous study conducted by Rahayaningrum et al., (2016) in which the average hospital inpatient cost was lower than average INA-CBGs tariff. Kurniawan et al., (2018) also found that unit cost calculated using activity based costing was lower than the real cost and INA-CBG's tariff. Lower actual hospital cost compared to set-payment system such as diagnosis-related group (DRG) was also found in previous study in breast cancer treatment in Germany (Jacobs et al., 2011).

The factors affecting the real costs of non-chemotherapy expenditure in cancer patients receiving chemotherapy were different among the three types of cancer and groups of severity level. There are difference healthcare services for the cancer cases with different level of severity. However, in general it can be said the factors mostly affecting the real costs were length of stay, number of procedure and type of hospitalized room class. Normally, the real costs in 1st type of hospitalized room were higher as compared to the real costs in 2nd and 3rd type of hospitalized room for all groups severity level. This is due to the higher tariff of accommodation in 1st type of hospitalized room. Based on the previous study by Kuderer et al., (2006), the number secondary diagnose has significant relationship with the risk of mortality. The patient in this condition needs optimal treatment during chemotherapy and post-chemotherapy, hence the costs of treatment including non-chemotherapy expenditure will be enhanced. Caggiano et al., (2004) developed model to estimate the probability of neutropenia, one of side effects of chemotherapy drugs. Age of patient, secondary diagnose, and initial status of patient can be the predictors of severe neutropenia. Therefore, it can be predicted that those factors have impact on the real costs in all groups of severity level. Length of stay is one important factor in predicting the real costs of hospital service. The previous study by Taheri et al., (2000) described the significant impact of length of stay on the total cost of hospitalization. By reducing 1 day of length of stay could reduce the total cost of treatment about $3 \%$. In our study, length of stay was the factor that significantly impacts the real costs in all groups of severity level. The longer the length of stay, the higher the costs. The number of procedure of treatment also enhances the length of stay and increases the costs. To simplify the treatment procedures and increase the effectiveness of healthcare service, the clinical pathway is necessary to be followed as the guideline in therapy. Clinical pathway is the detail and structured of treatment plan consists of important steps in patient treatment with specific clinical problem (Rotter et al., 2010). The effectiveness of healthcare services in the hospital has the impact on the success of surgery, prevention of complication, and better patient documentation, hence supports the role of clinical pathway to enhance the efficiency of resource utilization and treatment and finally 
affects the hospital real costs.

This study limited to compare the real cost with the INA-CBGs tariff rates from specific cases of breast cancer, cervical cancer, and nasopharyngeal cancer in one hospital. Future studies are encouraged to examine more diseases and multicenter hospital for better input for implementation of JKN.

In conclusion, there were significant differences of non-chemotherapy expenditures based on the real cost and INA-CBG's tariff rates, in which the costs were lower for the real cost. Factors which significantly affect the real cost were number of procedure, type of hospitalized room, and length of stay. The study supports the necessary of evaluation of the INA-CBG's tariff rates to accommodate the real healthcare expenditure. On the other hand, the hospital needs to evaluate the service quality of patient treatment by optimizing budget allocated by the health insurance.

\section{Funding support \\ None.}

\section{Statement conflict of Interest}

The authors declare that there is no conflict of interest regarding the publication of this article.

\section{References}

Ambarriani AS (2014). Hospital financial performance in the Indonesian national health insurance era. Review of Integrative Business and Economics Research, 4, pp 121-33.

American Cancer Society (2010). The Global Economic Cost of Cancer. Available at http://phrma-docs.phrma.org/sites/ default/files/pdf/08-17-2010_economic_impact_study.pdf

American Cancer Society (2013). Cancer Nasopharyngeal. http://www.cancer.org/acs/groups/cid/documents/ webcontent/003124-pdf.pdf.

Baba AI, Câtoi C (2007). Comparative oncology. Bucharest: Publishing House of the Romanian Academy.

Caggiano V, Weiss RV, Rickert TS, et al (2004). Incidence, cost, and mortality of neutropenia hospitalization associated with chemotherapy. Cancer, 103, 1916-24.

Dipiro JT, Talbert RL, Yee GC, et al (2008). Pharmacotherapy: A Pathophysiologic Approach Seventh Edition. TheMcGraw-Hill Companies, Inc. USA, 2085-2348.

Ferlay J, Soerjomataram I, Ervik M, et al (2012). GLOBOCAN 2012, Cancer Incidence and Mortality Worldwide, Version 1.0, IARC Cancer Base No. 11. http://globocan.iarc.fr.

Jacobs VR, Mayer S C, Paessens BJ, et al (2011). Comparison of actual hospital costs versus DRG revenues for in-patient treatment of febrile neutropenia during adjuvant anthracycline plus/minus taxane-based chemotherapy for primary breast cancer. Oncol Res Treat, 34, 614-8.

Kuderer NM, Dale DC, Crawford J, et al (2006). Mortality, morbidity, and cost associated with febrile neutropenia in adult cancer patients. Am Cancer Soc, 106, 2258-66.

Kurniawan S, Pribadi F (2018). Analysis unit cost in mild head injury patient with activity based costing method at the hopital in Yogyakarta. J Bus Res, 6, $105-16$.

Mboi N (2015). Indonesia: on the way to universal health care. Health Sys Reform, 1, 91-7.

Ministry of Health of Republic of Indonesia (2013). Regulation of Minister of Health of Republic Indonesia Number 69 of 2013. Available on http://www.depkes.go.id/resources/
download/general/PMK No. 69 of 2013 about the health service rate for the NHC program .pdf.

Ministry of Health of Republic of Indonesia (2014). Regulation of Minister of Health of Republic Indonesia Number 27 of 2014. Available on http://www.jkn.kemkes.go.id/attachment/ unduhan/PMK No. 20 about INA CBGs System technical guidelines .pdff.

Moore MA, Manan A, Chow KY, et al (2010). Cancer epidemiology and control in peninsular and island South-East Asia-past, present and future. Asian Pac J Cancer Prev, 11, 81-98.

Movva S, Rodriguez L, Arias-Pulido H, et al (2009). Novel chemotherapy approaches for cervical cancer. Cancer, $\mathbf{1 1 5}$, 3166-80.

National Team for The Acceleration of Poverty Reduction (2015). The Road to National Health Insurance (JKN). Secretariat of the Vice President of the Republic of Indonesia. Jakarta.

Puspitorini S, Kusumadewi S, Rosita L (2017). Prediction of disease case severity level to determine INA CBGs Rate. IOP Conference Series: Materials Science and Engineering, 185, 012012.

Rahayuningrum IO, Tamtomo D, Suryono A (2016). Comparison between hospital inpatient cost and INA-CBGs tariff of inpatient care in the National Health Insurance Scheme in Solo, Boyolali and Karanganyar Districts, Central Java. $J$ Health Policy Manag, 1, 109-19.

Rotter T, Kinsman L, James EL, et al (2010). Clinical pathways: effects on professional practice, patient outcomes, length of stay and hospital costs. Cochrane Database Syst Rev, 17, CD00663.

Taheri PA, Butz DA, Greenfield LJ (2000). Length of stay has minimal impact on the cost of hospital admission. J Am Coll Surg, 191,123-30.

Wahidin M, Noviani R, Hermawan S, et al (2012). Population-based cancer registration in Indonesia. Asian Pac J Cancer Prev, 13, 1709-10.

Waters HR, Hussey P (2004). Pricing health services for purchasers-a review of methods and experiences. Health Policy, 70, 175-84.

World Health Organization (2018). Cancer. Key Facts. Available from http://www.who.int/news-room/fact-sheets/detail/ cancer

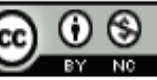

This work is licensed under a Creative Commons AttributionNon Commercial 4.0 International License. 